\title{
THE EQUIPMENT OF ARMOURED AMBULANCES IN NORTHERN IRELAND
}

\author{
Captain N. H. CLARK, M.B., Ch.B., R.A.M.C. \\ Regimental Medical Officer, 3 Bn. L.I.*
}

SUMMARY: All the equipment detailed in this paper is basic, easy to use, and has been positioned in the most logical manner in the vehicle. It is important to secure all equipment. as a speeding Saracen sets up considerable vibrations. Vital information must be summarised and displayed by means of diagrams and notices for easy reference.

\section{Introduction}

The emergency in Northern Ireland has now been in progress for some six and a half years, the standard armoured ambulance now in use is the Saracen A.P.C. modified as for use in general war, there is a very real necessity for armour despite the fact that the warring factions are "civilized", because of the risk of the ambulance being shot at, petrol-bombed, stoned or blown-up as has happened in the past.

The role of the Army in this Internal Security operation is very different to those in general war. This fact has been reflected in the wide range of special-to-role equipment which has been developed for the Army in Northern Ireland.

\section{The requirement}

The Armoured Ambulance is the operational transport for what is universally known in Northern Ireland as the "crash crew". This crash crew is the basic medical unit used for the recovery of operational casualties and consists of the following:-

a. A Medical Officer or senior Non-Commissioned Officer. b. Two Medical Orderlies. c. Driver.

In most cases in Northern Ireland it is possible to deliver an injured soldier direct to hospital, with no intermediate stages. This lays considerable emphasis on the immediate life-saving role of the crash crew. There is little or no need for prolonged treatment.

The medical role of this team can be summarised as follows:-

a. To administer life-saving first aid, that is, the maintaining of respiration via a clear airway and to stop haemorrhage.

b. To stabilise the patient's condition, by giving intra venous fluids, and pain relief if required.

c. To deliver the patient to hospital as quickly as possible.

It can be seen immediately that there is a current need for good military communications, to facilitate speed of action and to pass details of the casualty to the receiving hospital. In Belfast there is a medical net with direct communications between ambulances and the Military Wing of the Musgrave Park Hospital. In Londonderry because there is no military hospital close by, only one hospital, namely the Altnagelvin, we are on the unit net and the unit then get in touch with the hospital whilst the casualty is being evacuated. 


\section{The equipment}

After a considerable amount of trial for many years by many doctors, a provision of equipment can now be given, and it is to be found in the Northern Ireland I.S. Pack, as detailed in "Notes for Medical Officers", page 18, and A1 to A3. We have found it necessary to make a few additions to this equipment which are detailed below. The numbers in brackets refer to illusirations.

We found the following scale of equipment and layout inside the ambulance to be one very satisfactory solution. It has been used in action:-

a. Burns solution on rear door (dilute hibitane) and blankets to douse flames (1).

b. Street map, hanging above stretcher (2).

c. Street index, above radio for ease of reference when tasked (3).

d. Lists of equipment kept under seats for easy reference, on each seat back for items contained under that seat (4), for example, tracheostomy set under seat. Blood cross-matching bottles etc and local hospital forms under second seat.

e. Radio frequency chart, above radio (5).

f. Notification of casualties procedure, above radio (6).

g. Shell-dressings, behind seat backs (7).

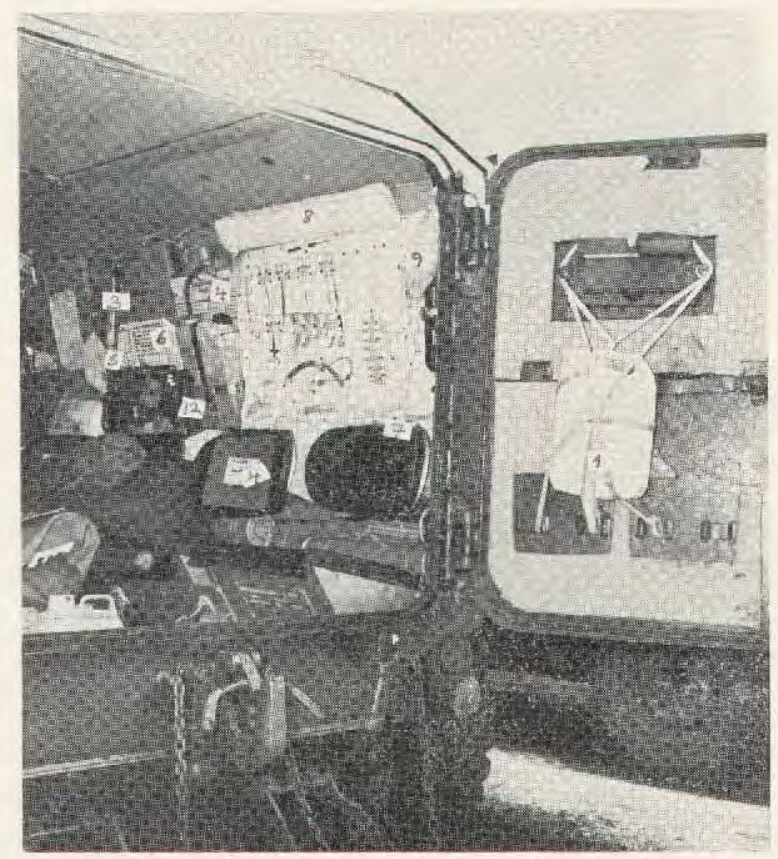

Fig. 1. Burns solution on door (1). Street index above radio (3). List of equipment under seats and tracheostomy set (4). Radio and frequency chart above (5). Noti-cas procedure above radio (6). Shell dressings behind seats (7). Splints (8). Drip fluids (9). Torch (12). Instrument display (16).

h. Splints, readily accessible with inflatable splints under seats (8).

j. Drip fluids $1 \times$ low mol wt Dextran, $1 \times$ normal saline and 1 Hartmann's solution at each end of the ambulance, spare fluids under seats (9). 


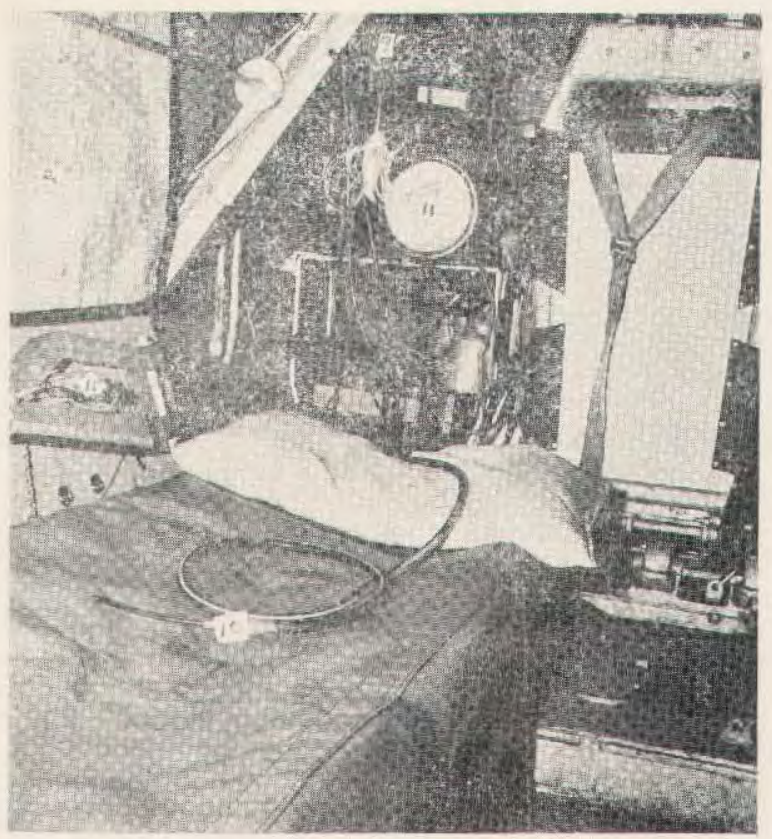

Fig. 2. Street map (2). Drip fluids at each end of ambulance (9). Sucker worked from windscreen wiper motor (10). Interior lights consisting of headlamp and standard lights (11).

k. Sucker, worked from windscreen wiper motor, incorporating the "Captain Brown" modification (10).

1. Efficient interior light-a converted vehicle headlamp, adjustable for use as a theatre light and small interior lights (standard) for overall illumination (11).

$\mathrm{m}$. Torch, in case of electrical failure (12).

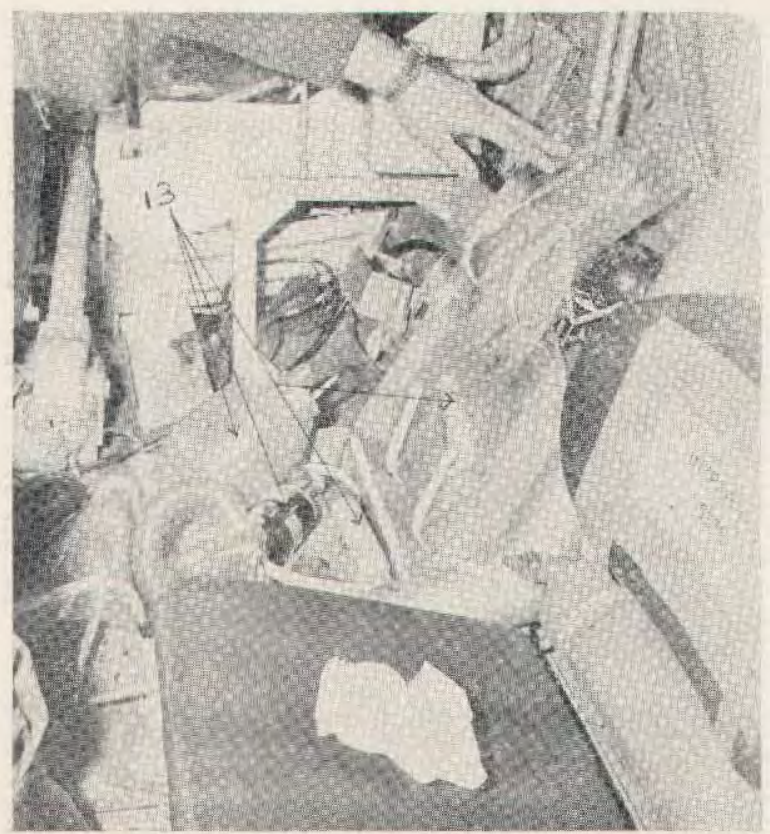

Fig. 3. Resuscitation set portogen modulaire, showing contents of box (13). Box is firmly attached to the vehicle. 
n. Resuscitation set portogen modulaire, this equipment is in a box firmly attached to the vehicle and comprising (13):-Miniature oxygen cylinder. Laryngoscope. Endotracheal tubes, both cuffed $8 \mathrm{~mm}$ and $9 \mathrm{~mm}$ with attachments (16). Ky jelly for tubes. Leardal Resusci folding bag, with facemask, it should always be remembered that the issue respirator filter can be fitted to this bag, when being used in the presence of noxious gasses. Airways (16).

o. Helmets - worn by all crew, there is a radio intercom facility for the commander and driver.

p. Extra stretchers - carried on exterior of the vehicle to allow maximum room inside (15).

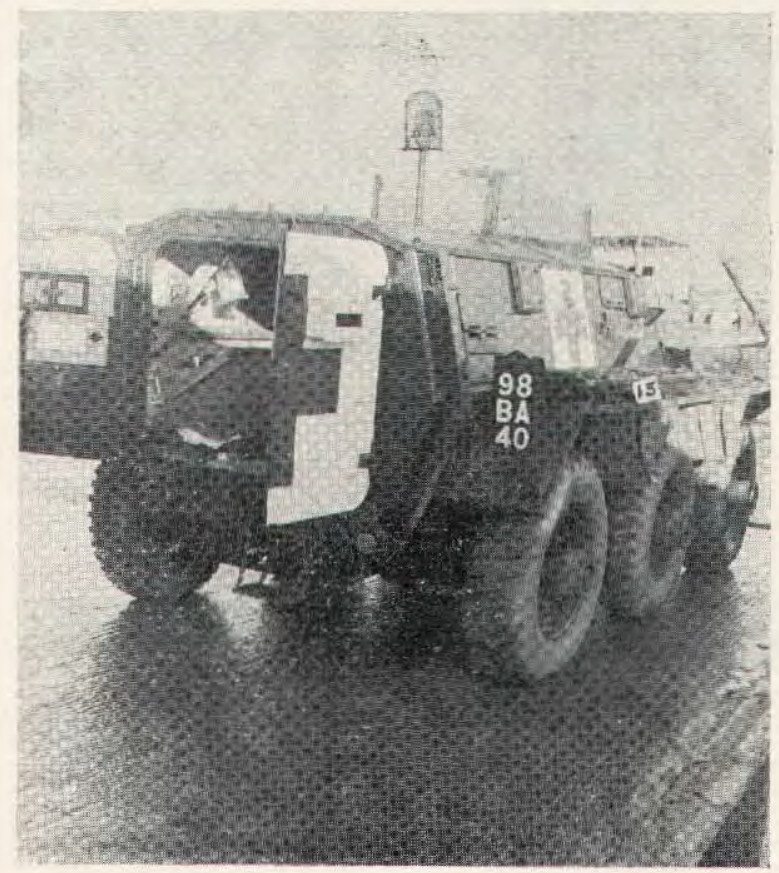

Fig. 4. Saracen ambulance showing extra stretchers (15) carried on the exterior of the vehicle to allow for maximum room inside.

q. "Capola Cover" over hatch (not seen in illustrations). There is at present a programme to fit proper commanders hatches to all Saracen Ambulances.

r. Instrument display " face up " for ease and speed of operation (16). The instruments are fastened to a board by plaster loops, and drawing pins, so that they can be taken down with the minimum of fuss, and after use can be easily replaced.

s. Heimlics valve and chest drain catheter (16).

\section{Drugs}

There are few drugs required in the life-saving role. Those that are needed would be under the direct control of the Regimental Medical Officer only and it is recommended that a pack be made up consisting of:-

a. Pethedine and/or Morphine/Pentazocine. b. Diazepam. c. Omnopon Syrettes. 
If the senior Non-Commissioned Officer is in charge, he may carry Omnopon on the Medical Officer's authority only. All the above drugs would be kept in the surgery and only taken out in emergencies. Minims, amethocaine and saline eyedrops are carried permanently in the vehicle.

\section{Recommendations}

It is recommended that the present adequate equipment scale should be supplemented with the extra items and modifications as mentioned in this article.

An established standard layout of medical equipment should be instituted for the Saracen ambulances, this would be of great convenience to all medical personnel; I have six ambulances in my area, and when we arrived all were layed out differently, with the result that whenever a particular instrument-piece of apparatus was required, valuable time was wasted looking for it, where-as with a fairly standard layout this could be obviated. This, I stress, is a personal view and many medical officers may disagree with it.

To ensure that all medical staff are made aware of the equipment carried and how to use it to its maximum efficiency, to this end, frequent practice and instruction are essential.

\section{Conclusion}

It has been proved beyond any doubt that swift skilled action by medically qualified people, operating from well equipped ambulances saves lives. The proximity of a modern hospital is no substitute for skilled life-saving first aid with the correct equipment at hand.

Hospitals are not always nearby in Northern Ireland, there can be some considerable delays in reaching them. The cities have heavy traffic which not even a Saracen can negotiate swiftly in rush hours, and unfortunately some hospitals also have no casualty departments.

Soldiers have the right to expect the highest possible standard of immediate first aid if they are injured on duty, and I hope that the contents of this article may be of some help in maintaining this high standard. 